$(\mathrm{P}=0.06+0.237$ no folate -0.023 smoking $)$

The ten most subjective adverse events:

- Upper abdominal pain was significantly related to corticosteroid use $(\mathrm{p}=0.047)(\mathrm{P}=0.183+0.109$ corticosteroid)

- Fatigue/malaise was significantly associated with smoking $(\mathrm{p}=$ 0.049) ( $\mathrm{P}=0.231-0.021$ smoking $)$

- Diarrhoea is significantly associated with age and a positive gasro-intestinal history, e.g. peptic ulcers and abdominal surgery $(\mathrm{p}=0.003$ and $\mathrm{p}=0.012)(\mathrm{P}=0.291-0.0037$ age + 0.087GI-history)

There were no significant associations between the other subjective adverse events (nausea, dizziness, headache, rash, stomatitis, cough and alopecia) and baseline characteristics.

Methotrexate withdrawal:

Significant factors predicting methotrexate withdrawal are folate suppletion, smoking and gastro-intestinal history. $(\mathrm{p}=$ $0.000,0.009$ and 0.019 respectively.

$(\mathrm{P}=0.124+0.236$ no folate -0.027 smoking $+0.103 \mathrm{GI}-$ history)

Conclusion Folates strongly protect against hepatotoxicity and methotrexate withdrawal, but not against subjective adverse events. An interesting finding is the relation between smoking and hepatotoxicty and fatigue/malaise. In smokers the methotrexate withdrawal was significantly less. A positive gastro-intestinal history and age were predictive factors for the occurrence of diarrhoea. In this study a declining creatinine clearance was no risk factor.

\section{FRI0015 AZATHIOPRINE WITHDRAWAL IN RHEUMATOID ARTHRITIS PATIENTS. ROLE OF TPMT GENETIC POLYMORPHISMS}

${ }^{1} \mathrm{H}$ Corominas, ${ }^{2} \mathrm{M}$ Domènech, ${ }^{1} \mathrm{~A}$ Laiz, ${ }^{1} \mathrm{M}$ Moreno, ${ }^{1} \mathrm{C}$ Geli, ${ }^{1} \mathrm{C}$ Diaz, ${ }^{1} \mathrm{G}$ Vázquez, ${ }^{2} \mathrm{M}$ Baiget. 'Unitat de Reumatolgia. Servei de Medicina Interna; ${ }^{2}$ Servei de Genètica, Hospital de La Santa Creu I Sant Pau, Barcelona, Catalonia-Spain

\subsection{6/annrheumdis-2001.1144}

Background Dose-dependent Azathioprine's bone marrow toxicity is widely accepted, although identification of the genetic polimorphysm of the Thiopurine methyltransferase (TPMT) is being recently recognised.

Objectives The aim of the study was to investigate, if the appearance of drug related side effects, such as haematologic toxicity was due to the presence of allelic variants of the TPMT gene.

Methods 111 RA patients DNA's from WBC were amplified by PCR. Digestion with enzymes (MwoI and Acc) were performed, to identify the different allelic variants of the TPMT gene. MwoI digestion of the $284 \mathrm{bp}$ PCR product resulted in fragments that either remained intact (mutant allele A460) or were cut in two segments of $267 \mathrm{bp}$ and $17 \mathrm{bp}$ (wild type allele G460A). AccI restriction site was present when the G719 mutation existed, the PCR products containing this mutation were cleaved (207 bp and 86 bp fragments) when digested with AccI, while the wild type fragments (A719) were not digested. Results were compared with 105 DNA samples from healthy donors. $\mathrm{X} 2$ tests on genotype frequencies and $\mathrm{p}<0.05$ was statistically significant.

Results $9.5 \%$ of healthy controls and $7.2 \%$ RA patients were heterozygous for a mutant allele of the TPMT gene. The most frequent variant in both groups was the TPMT 3A (G460A, A719G). Within the 111 RA, 40 of them had followed Aza therapy. 8 of them were still following this therapy, and 32 had to withdrawal Azathioprine therapy due to non response $(\mathrm{n}=$ 27) or adverse side effects $(n=5)$ : These last 5 patients were homozygous for the Wild type TPMT allele.

Conclusion TPMT genotype is to identify patients at risk of severe bone marrow toxicity if treated with Aza, Our study reveals that, severe side effects due to Azathioprine cannot be explained by the presence of these two mutant alleles.

\section{REFERENCES}

1 Kerstens PJ, Stolk JN, De Abreu RA, Lambooy LHJ, van de Putte LBA, Boeermooms A. Azathioprine-related bone marrow toxicity and low activities of purine enzymes in patients with rheumatoid arthritis. Arthritis Rheum. 1995;38:142-5

2 Yates CR, Krynetski EY, Loennechen T, Fessing MY, Tai HL, Pui CH, Relling MV Evans WE. Molecular diagnosis of thiopurine S-methyltransferase deficiency: genetic basis for azathioprine and mercaptopurine intolerance. Ann Intern Med. 1997;126:608-14

\section{FRI0016 FACTORS PREDICTING METHOTREXATE DOSE AND EFFECTIVITY}

${ }^{1} \mathrm{M}$ Hoekstra, ${ }^{2} \mathrm{~A}$ Van Ede, ${ }^{1} \mathrm{C}$ Haagsma, ${ }^{1} \mathrm{M}$ Van de Laar, ${ }^{2} \mathrm{R}$ Laan. ${ }^{1}$ Department of Rheumatology, Medisch Spectrum Twente, Enschede, The Netherlands; '2Department of Rheumatology, University Hospital St Radboud, Nijmegen, The Netherlands

\subsection{6/annrheumdis-2001.1145}

Background Methotrexate is the most effective treatment in rheumatoid arthritis. Dose and clinical effect are related.

Objectives To determine predictive factors for reaching a dose of $>12.5 \mathrm{mg} /$ week and effectivity.

Methods Data from a double-blind placebo controlled multicenter study on patients with active rheumatoid arthritis were used. In this trial the effect of folic acid $(1 \square 2 \mathrm{mg} /$ day), folinic acid (2.5 $\mathrm{mg} /$ week) and placebo along methotrexate therapy (7.5maximum $25 \mathrm{mg} /$ week) was compared. The patients never had methotrexate before, had active disease and a creatinine clearance $>50 \mathrm{ml} / \mathrm{min}$. The three groups contained 133, 141 and 137 patients respectively. The follow-up was 48 weeks.

By means of multiple stepwise regression analysis we studied the relation between baseline variables and the following: methotrexate dose $>12.5 \mathrm{mg} /$ week and effectivity (lowest DAS1.08).

Results Effectivity:

We found no significant relation between baseline characteristics and effectivity.

When we only look at a change in DAS $>1.08$ the disease duration (months) is significantly associated $(\mathrm{p}=0.035)$

$(\mathrm{P}=0.678+0.0015$ disease duration $)$

Methotrexate dose $>12.5 \mathrm{mg} /$ week:

Reaching a dose $>12.5 \mathrm{mg} /$ week is significantly associated with folate suppletion $(\mathrm{p}<0.0001)$ and negatively with gastrointestinal history, e.g. peptic ulcers and abdominal surgery $(\mathrm{p}=$ 0.037).

$$
(\mathrm{P}=0.678-0.292 \text { no folate }-0.013 \text { GI-history })
$$

Conclusion Baseline characteristics do not predict effectivity. A positive gastro-intestinal history had a small negative effect on methotrexate dose. Reaching a high dose methotrexate is mainly predicted by folate suppletion. This is most likely explained by a reduction of toxicity. Our results suggest that when using folate adjuvant therapy, a weekly methotrexate dose of $>12.5 \mathrm{mg} /$ week will be reached in $68 \%$. Thus, with adjuvant folate, starting methotrexate therapy at a weekly dose of $15 \mathrm{mg}$ seems justified. 